\title{
Reconfigurações do espaço rural e do cotidiano familiar: os sujeitos e suas práticas com as tecnologias de comunicação'
}

\author{
Ana Carolina D. Escosteguy \\ Universidade Federal de Santa Maria - Santa Maria - RS - Brasil \\ ORCID: https://orcid.org/0000-0002-0361-6404 \\ Ângela Cristina Trevisan Felippi \\ Universidade de Santa Cruz Do Sul - Santa Cruz Do Sul - RS - Brasil \\ ORCID: https://orcid.org/0000-0003-3545-0215 \\ Lírian Sifuentes \\ Televisão Educativa de Porto Alegre - Porto Alegre - RS - Brasil \\ ORCID: https://orcid.org/0000-0001-6329-7364
}

\begin{abstract}
Resumo
No artigo se apresenta pesquisa que investigou a apropriação e a incorporação das tecnologias de comunicação (SILVERSTONE, HIRSCH e MORLEY, 1996), por famílias da agricultura, em um meio rural específico do Sul do Brasil. A perspectiva de análise é comunicacional, mas com abordagem socioantropológica, que faz dialogar duas áreas distintas de conhecimento - Comunicação e Desenvolvimento Regional. A pesquisa original se desenvolveu entre 2014 e 2018, envolvendo pesquisa bibliográfica e de campo, articulando um conjunto de técnicas como: formulário, registro fotográfico, relato de campo e entrevista. A análise teve por base os mapas de comunicação de Jesús Martín-Barbero (2018), e articulou as chaves teórico-analíticas da institucionalidade, socialidade, tecnicidade, ritualidade, espacialidade, temporalidade e mobilidade. Os resultados apontam para a existência de movimentos contraditórios de inclusão e exclusão digital, com existência de aspectos facilitadores e impeditivos de acesso às tecnologias de comunicação; para a forte mediação do espaço e do tempo na apropriação e incorporação das tecnologias; e para a constituição de uma certa ruralidade para a qual as TICs são componentes importantes. Palavras-chave: Tecnologias da Informação e Comunicação. Rural. Espaço. Mediações.
\end{abstract}

\footnotetext{
1 Uma primeira versão deste texto foi apresentada ao Grupo de trabalho Tecnologia e Ruralidades Contemporâneas da XIII Reunião de Antropologia do Mercosul, realizada em Porto Alegre (RS), entre 22 e 25 de julho de 2019, sob o título Reconfigurações do espaço rural e do cotidiano familiar: O papel das tecnologias de comunicação.
} 


\title{
Reconfigurations of rural space and family daily life: subjects and their practices with communications technologies
}

\begin{abstract}
This paper presents research which has investigated the appropriation and incorporation of communications technologies (SILVERSTONE, HIRSCH and MORLEY, 1996) by farming families in a specific rural area of Southern Brazil. The communicational perspective is adopted, associated with a socio-anthropological methodology. At the same time, the study brought into dialogue two distinct areas of knowledge - Communication and Regional Development. The original research was developed between 2014 to 2018, embrancing bibliographic and field research, and articulating a set of techniques such as form, photographic record, field report and interview. The analysis was based on the proposal of Jesús Martín-Barbero (2018), articulating the following analytical keys: institucionality, sociality, technicity, rituality, spatiality, temporality and mobility. The results point to the existence of contradictories movements of digital inclusion and exclusion, considering different aspects of access to communication technologies; to the strong mediation of space and time in the appropriation and incorporation of technologies; and to the constitution of a particular rurality for which ICTs are important components.
\end{abstract}

Keywords: Information and Communications Technologies. Rural. Space. Mediations.

Reconfiguraciones del espacio rural y la vida cotidiana familiar: los sujetos y sus prácticas con las tecnologías de la comunicación

\section{Resumen}

Este artículo presenta investigación que estudió la apropiación y incorporación de tecnologías de comunicación (SILVERSTONE, HIRSCH Y MORLEY, 1996) por parte de familias de agricultores en área rural específica del Sur de Brasil. La perspectiva de análisis es comunicacional, pero con un enfoque socio antropológico, que pone en diálogo dos áreas distintas de conocimiento: Comunicación y Desarrollo Regional. La investigación original se desarrolló entre 2014-2018, involucrando investigación bibliográfica y de campo, articulando un conjunto de técnicas como formulario, registro fotográfico, informe de campo y entrevista. El análisis se basó en los mapas de comunicación de Jesús Martín-Barbero (2018), y articuló las claves teóricas y analíticas de la institucionalidad, sociabilidad, tecnicidad, ritualidad, espacialidad, temporalidad y movilidad. Los resultados apuntan a la existencia de movimientos contradictorios de inclusión y exclusión digital, asociados a aspectos que facilitan e impiden el acceso a las tecnologías de comunicación; a la fuerte mediación del espacio y del tiempo en la apropiación e incorporación de tecnologías; y a la constitución de una determinada ruralidad para la cual las TIC son componentes importantes.

Palabras clave: Tecnologías de la Información y Comunicación. Rural. Espacio. Mediaciones.

\section{Situando a pesquisa}

Estudar uma realidade social envolve variadas perspectivas, e possibilidades diversas de aproximações ao objeto. Nosso interesse $e^{2}$ é conhecer a apropriação e a

\footnotetext{
2 Este artigo se origina da pesquisa Tecnologias de comunicação nas práticas cotidianas: $O$ caso de famílias relacionadas à cadeia agroindustrial do tabaco (Chamada Universal MCTI/CNPq n 14/2014), coordenada por Ana Carolina D. Escosteguy. O estudo foi realizado de modo interdisciplinar e interinstitucional com pesquisadores do PPG em Comunicação Social da PUCRS - e depois passa a ser sediado no PPGCOM da UFSM - e do PPG em Desenvolvimento Regional da UNISC.
} 
incorporação ${ }^{3}$ das tecnologias de comunicação em um meio rural específico a partir de um ponto de vista primordialmente comunicacional, mas com uma abordagem socioantropológica. Contudo, duas áreas distintas de conhecimento - Comunicação e Desenvolvimento Regional - foram articuladas, com a ambição de alcançar uma proposta de interdisciplinaridade, possibilitando o tratamento de uma realidade que não é compartimentada nem disciplinar.

As relações entre Comunicação e Desenvolvimento não são recentes; datam de meados do século passado, quando as áreas e suas práticas são articuladas no projeto desenvolvimentista latino-americano. No entanto, nas últimas décadas uma virada crítica tem permitido o alargamento dos objetos e perspectivas de análise, bem como estudos comprometidos com a realidade social em análise.

É o caso da pesquisa que se apresenta neste artigo, cujo grupo estudado é constituído por famílias agricultoras pertencentes à cadeia agroindustrial do tabaco, e está inserido em um contexto determinante para a apropriação e incorporação que fazem de tecnologias de comunicação. A pesquisa desenvolvida entre 2014 e 2018 procurou cumprir com seu compromisso social, investigando a realidade da agricultura familiar e os movimentos de inclusão e exclusão tecnológica pelo qual passa esse grupo social em uma determinada região.

A pesquisa estudou sete famílias que vivem em Vale do Sol-RS, município em que $88,72 \%$ da população - de 11.077 pessoas $^{4}$ - moram no meio rural (IBGE, 2010). Além disso, a Microrregião de Santa Cruz do Sul5, onde se localiza Vale do Sol, é responsável por expressiva produção de tabaco ${ }^{6}$, assim como por seu beneficiamento e industrialização. Caracteriza-se pela agricultura tipicamente familiar, com pequenas propriedades (FELIPPI; OLIVEIRA; DORNELLES, 2019). As famílias são compostas pelos pais, filhos/as jovens ou crianças ${ }^{7}$, noras, e em quatro propriedades, havia a presença dos avós. Ao todo, foram 35 sujeitos de pesquisa, que têm em comum a condição de vida no espaço rural, estarem relacionados à agricultura familiar, serem naturais de Vale do Sol e terem predominantemente origem germânica.

\footnotetext{
3 Usamos esses conceitos a partir de Silverstone, Hirsch e Morley (1996), entendendo apropriação como a posse/aquisição do artefato, permitindo a chegada da tecnologia na casa, e incorporação como a integração das mídias no cotidiano das famílias.

${ }^{4}$ A população é quase igualmente dividida entre homens e mulheres, católicos e luteranos, e praticamente a totalidade se autodeclara branca (IBGE-CIDADES, 2018). A maior parte dos moradores tem origem germânica.

${ }^{5}$ A Microrregião de Santa Cruz do Sul é uma regionalização oficial do IBGE.

6 "A cadeia agroindustrial do tabaco opera numa dicotomia configurada por políticas de combate ao tabagismo, elaboradas em escala mundial e, no Brasil, implementadas pelo governo federal, e estratégias de incentivo à instalação de novos parques produtivos. Nesse embate, têm sido vencedoras as tentativas de manutenção e crescimento da agroindústria do tabaco (SILVEIRA et al., 2011), em que pesem os entraves que a atividade carrega." (FELIPPI; ESCOSTEGUY, 2017, p. 145).

7 Observamos essa condição junto as crianças, embora, de modo sistemático, elas não tenham sido entrevistadas. Ou seja, nas nossas visitas, estivemos com elas e conversamos a respeito, mas elas não fizeram parte do conjunto de sujeitos entrevistados.
} 


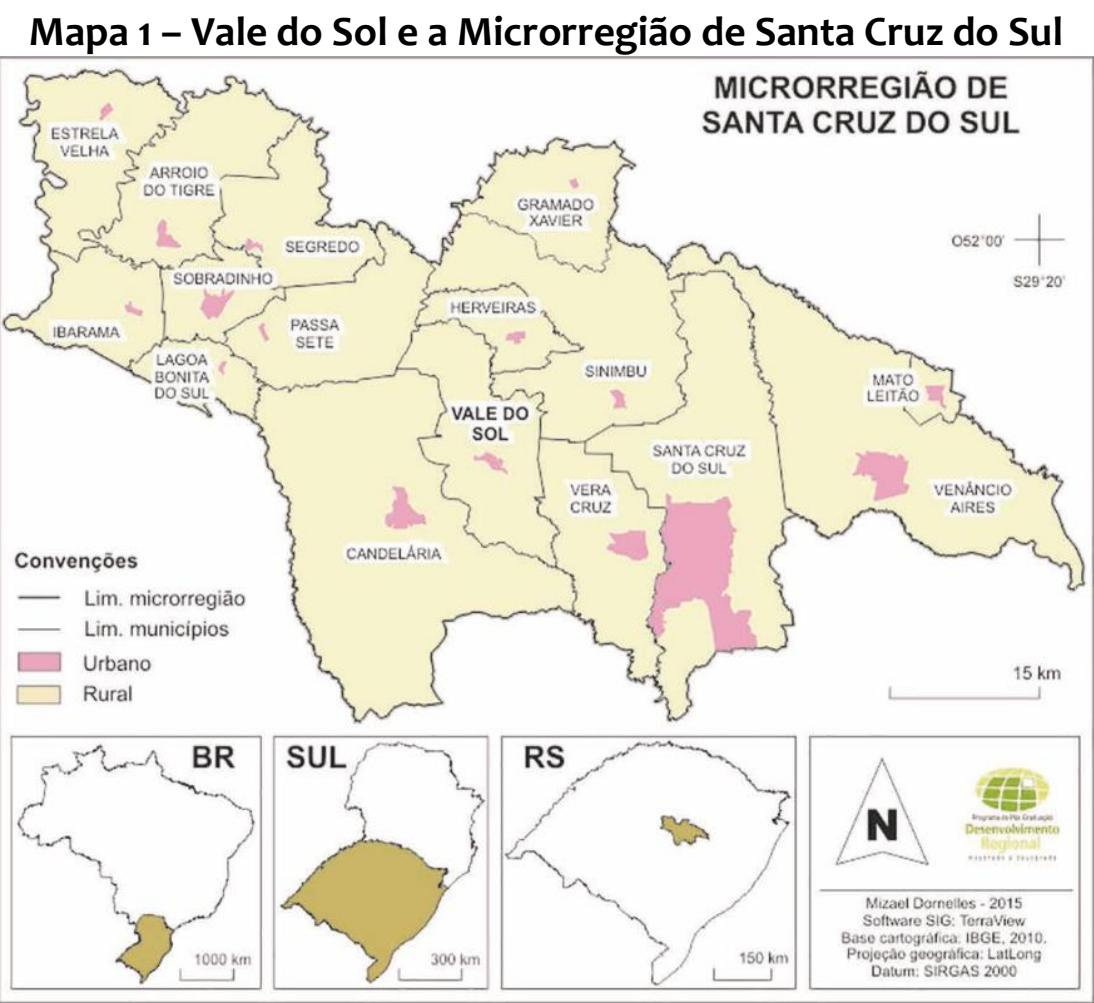

Fonte: FELIPPI; OLIVEIRA; DORNELLES, 2019, p. 54.

As tecnologias de informação e comunicação tradicionais - rádio, televisão, revista, jornal e livro - fazem parte do espaço rural de Vale do Sol, com menor ou maior presença, há algumas décadas, a exemplo do que ocorre em outros contextos rurais brasileiros. No entanto, quando se trata de nova mídia ${ }^{8}$ - computador, tablet, celular e internet -, a posse é recente. Pode-se dizer que a nova mídia é realidade no rural brasileiro de modo geral na década de 2010, percepção corroborada por levantamentos que indicam seu recente crescimento. ${ }^{9}$

Pesquisa nacional da CETIC destaca que em 2018, 85\% dos domicílios rurais tinham celular, índice abaixo ao encontrado no meio urbano, que era de $94 \%$ (CETIC, 2018). A posse do computador de mesa existe em $7 \%$ dos lares do rural, do computador móvel, em 11\%, e do tablet, em $7 \%$. Para efeito de comparação com os equipamentos da mídia tradicional, a televisão está presente em $93 \%$ das residências localizadas na área rural, enquanto o rádio está em $64 \%{ }^{10}$. Todos os índices do rural estão abaixo dos índices urbanos, com exceção do rádio, com dois pontos percentuais acima. Com relação ao acesso à internet, dos 126,9 milhões de brasileiros que acessaram a rede (acesso nos três meses anteriores à realização da pesquisa), cerca de 49 milhões moram na área rural. Mas a desigualdade brasileira no acesso às tecnologias de comunicação não diz respeito somente à área de moradia, como

\footnotetext{
8 Empregamos a terminologia de Dizard (2000), sem, no entanto, desconsiderar o fato de haver diversas possibilidades de nomeação, carregando significados específicos.

9 Em cetic.br podem ser visualizadas pesquisas progressivas de acesso às tecnologias de comunicação por domicílios e por usuários.

${ }_{10}$ Vale a menção que a pesquisa mede a presença do equipamento (rádio e TV, por exemplo) e não a presença enquanto mídia que pode ser acessada por distintos artefatos por conta do contexto de convergência tecnológica.
} 
também à condição de renda. Num corte por classe social, a pesquisa da CETIC mostra que o acesso à internet é diferenciado de acordo com a classe. Mais de $90 \%$ dos componentes das classes $A$ e $B$ apresentam acesso à rede; $76 \%$ da classe $C$ têm acesso e somente $48 \%$ da classe $D / E$ contam com internet ${ }^{11}$. Ainda, vale menção a outros dois dados da pesquisa: um, que aponta que $77 \%$ dos usuários de internet moradores de área rural acessam à rede exclusivamente por meio do celular; e, o outro que indica que $61 \%$ dos usuários da classe $C$ e $81 \%$ da D/E também têm internet somente por celular. (CETIC, 2018).

Embora não se tenha dados precisos sobre o acesso dessas tecnologias na Microrregião de Santa Cruz e, especificamente, em Vale do Sol, uma vez que os dados regionais são dispersos e têm origem em diferentes órgãos (como Anatel, Ministério das Comunicações etc) ou não condizem com a realidade, como ocorre com os informes oficiais sobre cobertura de sinal de celular, sabemos que há incremento dessas tecnologias na região. No entanto, os dados nacionais revelam a penetração desses meios na vida dos brasileiros, entre eles, daqueles que vivem no meio rural. Também mostram, no entanto, diferenças relevantes no acesso às chamadas TICs Tecnologias de Informação e Comunicação - por essa população, relacionadas sobretudo às escolhas familiares de aquisição de bens, balizadas por questões de renda, acesso pleno e valoração da tecnologia, que foram aprofundadas no estudo empírico. Para tanto, investigamos tanto a mídia tradicional, quanto a nova mídia, muito embora a segunda tenha sido objeto de maior atenção para este artigo. Entendemos que, independentemente do tempo de existência de cada tecnologia, esses artefatos tecnológicos se inter-relacionam, convivendo, complementando-se, concorrendo e sobrepondo-se.

Antes de tudo, é importante demarcar a compreensão de tecnologia adotada e o modo como se entende sua presença na vida social contemporânea. De um lado, é bastante difundida uma ideia de "determinismo" tecnológico, em que os aparatos são, por si só, elementos definidores das experiências sociais na atualidade. Essa visão toma "a tecnologia como uma variável independente, como um processo linear onde ela determina os aspectos sociais e contribui para o progresso da humanidade" (QUIROZ; VÉLEZ, 2014, p. 130). De outro, é relativamente corrente um entendimento "construtivista" da tecnologia que busca "revestir de elementos sociais e culturais os processos de desenvolvimento tecnológico e os dispositivos culturais que subjazem à sua produção e consumo, assim como também identificar os mecanismos pelos quais a tecnologia configura uma cultura e formas de proceder e atuar socialmente" (Ibid., p. 130). Assim, nessa última abordagem, os atores sociais são parte ativa e imprescindível ao darem sentido aos aparatos, que não existem de fato se não em um processo sociocultural. Assim como Wajcman (2017, p. 50), julgamos que "todas as tecnologias são intrinsecamente sociais já que são desenhadas, produzidas, utilizadas e governadas por pessoas".

Valemo-nos, também, do que compreende Martín-Barbero (2009a, p. 148) sobre a "tecnologia": "o que estamos nomeando não é somente uma coisa, mas um ‘âmbito' extremamente potente, tanto de linguagens como de ações, tanto de

${ }^{11}$ Em que pese a pesquisa não se dedicou a identificar a classe social das famílias estudadas, a partir de levantamento sociocultural é possível situar os sujeitos pesquisados num comportamento de consumo de classe média, o que os aproximaria das classes $\mathrm{C}$ e D/E. 
dinâmicas sociais, políticas e culturais, quanto de interrogações sobre o que significa o social hoje". Tem significado, assim, para além do instrumental, constituindo, a partir dos usos a ela dado, novas formas de sociabilidade, que se dão de modo "ritualizado", seja em momentos ordinários ou extraordinários da vida dos sujeitos. E, em nível macro, compõe o "entorno tecnocomunicativo" (MARTíN-BARBERO, 2018) que engloba a realidade social, constituindo um ecossistema comunicativo que estrutura e constitui a vida social.

O autor espanhol-colombiano tem especial importância em nossa pesquisa ${ }^{12}$, e no artigo aqui apresentado, pois embasa nossa trama analítica e, por conseguinte, a leitura dos dados que trazemos neste artigo, a partir da articulação entre dois de seus mapas. Extraímos do Mapa das Mediações Comunicativas da Cultura (MARTíNBARBERO, 2003) as seguintes chaves teórico-analíticas: a institucionalidade, a socialidade, a tecnicidade e a ritualidade; e do Mapa das Mutações Comunicativas e Culturais (MARTÍN-BARBERO, 2009b): a espacialidade, a temporalidade e a mobilidade. Essa construção já foi discutida de forma mais aprofundada em outro espaço (ESCOSTEGUY, 2019), e será retomada sucintamente na seção seguinte.

Metodologicamente, desenvolvemos um protocolo formado por uma variedade de instrumentos, construído a partir de constante reflexão epistemológica13, aplicado ao longo da realização da pesquisa, de 2014 a 2018. No início da pesquisa de campo desenvolveu-se uma entrevista aberta, ou conversa coletiva, guiada por poucas questões gerais, que tinha o objetivo de introduzir a pesquisa e apresentar a equipe aos participantes. Nessa primeira visita, aplicamos formulários de família e individuais. O primeiro, focado em constituir um retrato da propriedade e da casa, incluindo aí questões acerca da posse de tecnologias domésticas, laborais e de comunicação; e, o outro, em conhecer aspectos de trajetória de vida, educacionais e preferências midiáticas dos pesquisados.

A segunda visita teve o objetivo de realizarmos entrevistas semiestruturadas com os sujeitos, baseadas em quatro eixos: 1) experiências de apropriação das TICs entrada dos meios nos lares; 2) incorporação das TICs no cotidiano; 3) relação com o meio de comunicação favorito; 4) relação entre o trabalho e as TICS.

Tanto na primeira quanto na segunda incursão à casa de cada uma das sete famílias, foram feitas fotografias das propriedades, das casas e dos participantes. Inicialmente, o objetivo era somente possuirmos meios de ilustrar a pesquisa empírica. Posteriormente, porém, o registro fotográfico ganhou importância, e passamos a valorizar a dinâmica envolvida no ato de fotografar, especialmente quando pedíamos para que nos mostrassem e posassem junto à sua TIC preferida. Outra utilidade foi a produção de um foto-livro personalizado para cada família, com fotografias da localidade, das propriedades, dos informantes e dos meios de comunicação, entregues em uma terceira visita, em 2017, ocasião em que pudemos atualizar dados, e em que se notou o crescimento no uso, especialmente, da internet, e de aplicativos, como o WhatsApp. Nessa mesma ocasião, demos um retorno ao

\footnotetext{
12 Para além da importância desse autor no campo da comunicação, também, na área do desenvolvimento, suas contribuições vêm sendo paulatinamente incorporadas.

13 Visto a importância dada aos aspectos metodológicos pelo grupo de investigadores responsáveis pela pesquisa, ainda mais por se tratar de um estudo empírico, interdisciplinar e interinstitucional, alguns artigos foram dedicados a essa reflexão nos últimos anos (ESCOSTEGUY; SIFUENTES; BIANCHINI, 2016; SIFUENTES; RIBAS; BIANCHINI, 2019).
} 
grupo pesquisado do que até aquele momento tinha sido produzido a respeito. Após as três visitas, foram elaborados relatos de campo, com a percepção dos pesquisadores sobre os sujeitos e o espaço investigados.

A seguir, nossos achados empíricos são pensados e apresentados a partir das mediações de Jesús Martín-Barbero anteriormente destacadas: institucionalidade, socialidade, ritualidade, temporalidade, espacialidade e mobilidade. Como será possível perceber, há um entrecruzamento e mesmo uma sobreposição entre elas, especialmente, quando se observa determinadas práticas. Por exemplo, a escuta do rádio no galpão, ao mesmo tempo, demonstra uma certa temporalidade - alguns meses do ano são mais ocupados com o rádio -, uma ritualidade própria - enquanto se seca o fumo, se ouve rádio -, uma determinada espacialidade - o espaço privilegiado para ouvir rádio é o galpão -, e uma mobilidade particular - com a escuta do rádio é possível se "transportar" imaginariamente do galpão para outros lugares. Portanto, quando julgamos pertinente, uma prática relacionada à mídia é lida à luz de mais de uma mediação, com enfoques diferentes.

\section{Mediações barberianas: as chaves analíticas}

As mediações consideradas aqui podem ser sinteticamente definidas da seguinte maneira: a) a institucionalidade, conformada a partir de estruturas e mecanismos reguladores de práticas e comportamentos, existentes anteriormente ao contato das famílias com as TICs, mas desempenhando funções e fazendo sentido nessa relação; b) a socialidade, constituída e constituinte por/de sistemas de referência socioculturais que afetam o tipo de incorporação que se faz das TICs, assim como são afetadas por elas; c) a ritualidade refere-se às práticas acionadas nos usos regulares e repetidos que se faz das tecnologias de comunicação, tornando-se rotinas e, muitas vezes, interferindo na organização de outras atividades domésticas, assim como laborais; d) a temporalidade, transformada pelos usos feitos das tecnologias, por vezes considerando-se haver ganhos e, em outras, perdas, mas geralmente positivada ou negativada pelos sujeitos; e) a espacialidade coloca em destaque o impacto dos espaços nas relações que se tem com as TICs, muitas vezes reconfigurando-o e deixando claro que eles são produzidos socialmente; f) a mobilidade está relacionada ao trânsito constante, tanto físico quanto virtual, entre diferentes espaços e tempos, com frequência significando uma "viagem", real ou imaginária, sobretudo, ao universo urbano. Por fim, a mediação da tecnicidade, aqui, ocupa um lugar central, referindo-se a um modo de relação com o mundo, em que as tecnologias se empenham em estabelecer uma gramática de relação com o mundo, permeando as experiências do sujeito. Por isso, dada a nossa temática de estudo, não será analisada de forma separada, sendo uma mediação que engendra e promove as demais.

Conforme dito anteriormente, a partir de dois mapas desenhados por Jesús Martín-Barbero, elaboramos um terceiro, o Mapa de chaves teórico-analíticas para um estudo socioantropológico de TICS, que articula as mediações que se mostraram presentes na realidade estudada. 


\section{Figura 1 - Mapa de chaves teórico-analíticas para um estudo socioantropológico de TICs}

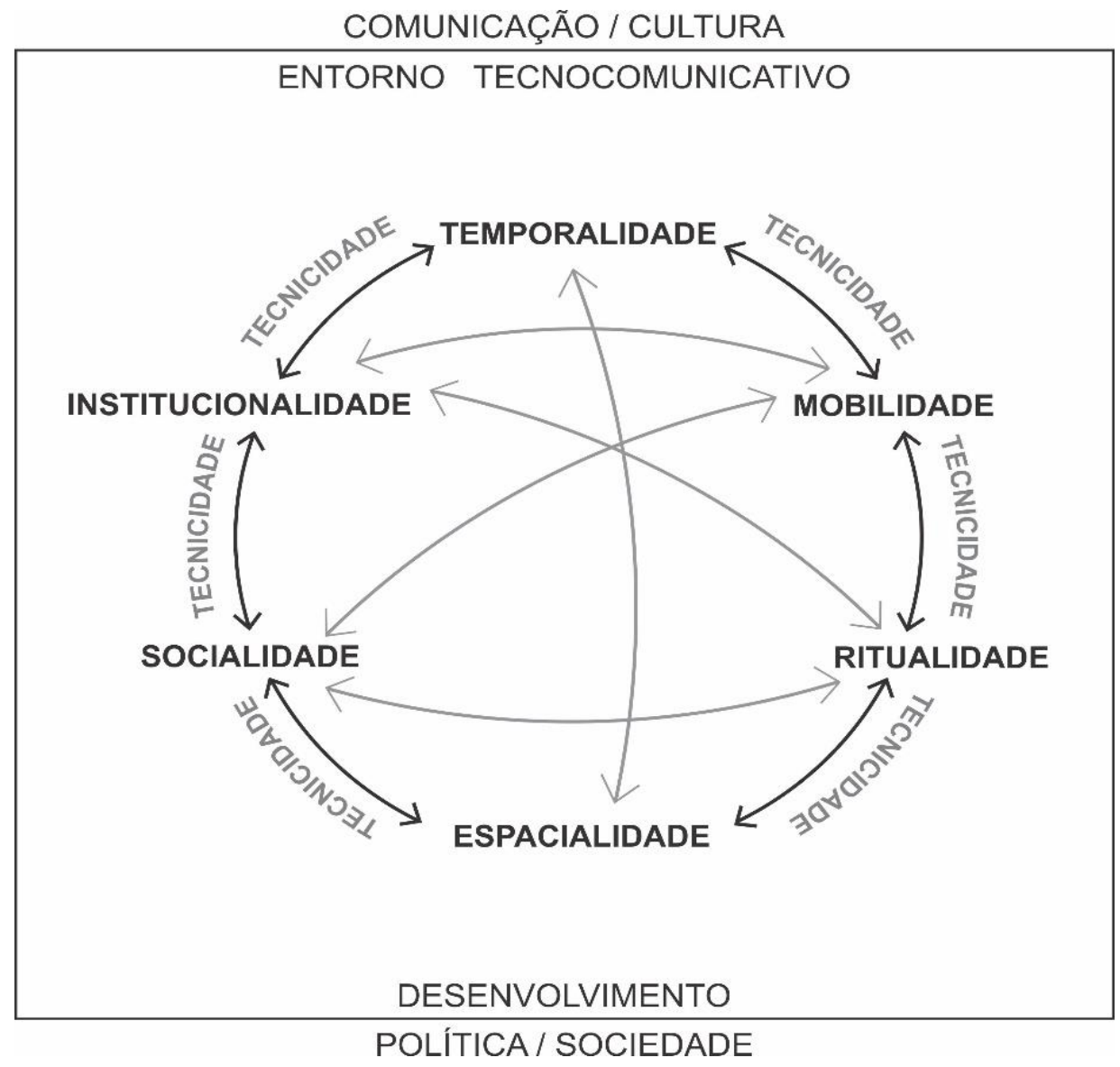

Fonte: ESCOSTEGUY, 2019, p. 29.

Na sequência, apresentamos a análise das mediações e suas articulações, representadas visualmente na Figura 1.

\subsection{Institucionalidade}

Primeiramente, destacamos o papel definidor do mercado e do Estado no que diz respeito ao acesso às tecnologias de comunicação, limitando, por um lado, o uso que se poderá fazer delas, e, por outro, ensejando outras apropriações e incorporações, visto a elaboração de modos criativos/alternativos para esse uso.

No caso da nova mídia, a seguir, trazemos um mapa da localização das antenas de operadoras de celular no município do Vale do Sol, assim como a distribuição geográfica das sete propriedades investigadas. O mapa das antenas de celular exemplifica parte da ação do Estado e Mercado, que tem este tipo de materialidade no caso das mídias eletrônicas. Isto porque as políticas de regulação da comunicação no país e sua implementação no território estudado - a microrregião de Santa Cruz do Sul - configuram parte da mediação da institucionalidade. 


\section{Mapa 2 - Mapa da localização das antenas e das famílias pesquisadas em Vale do Sol}

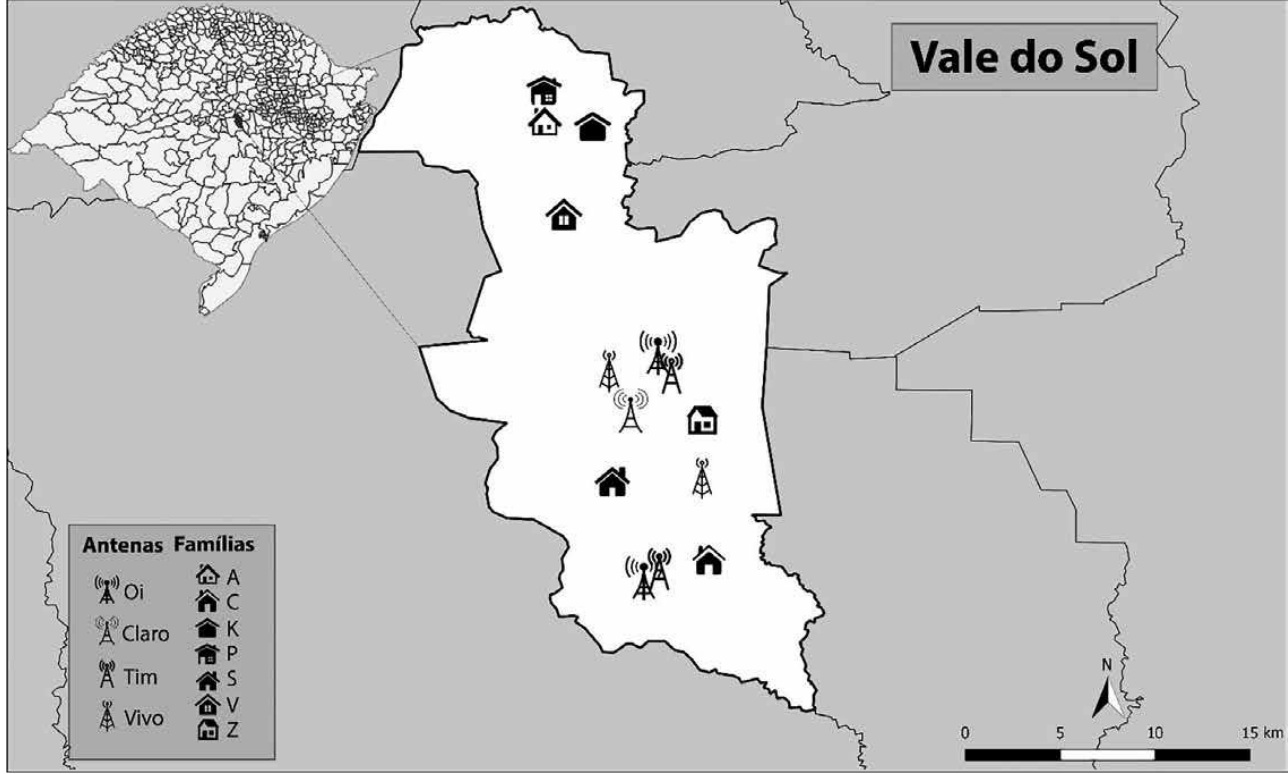

Fonte: FELIPPI; OLIVEIRA; DORNELLES, 2019, p. 70.

A partir do mapa, podemos identificar que as famílias $\mathrm{A}, \mathrm{K}, \mathrm{V}$ e $\mathrm{P}^{14}$ estão mais distantes das antenas. Já as famílias C, S e Z vivem mais próximas dos locais onde estão instalados esses aparatos. Assim, a localização afeta a facilidade ou a dificuldade vivenciada para ter acesso ao sinal de telefone. Desse modo, notamos aí uma primeira atuação da institucionalidade, impactando nas possibilidades de uso.

No que se refere ao sinal de telefone, verificamos, entre as famílias, um tipo de experiência pouco comum quando pensamos em acesso às tecnologias, uma vez que elas vivenciaram um retrocesso. Quando os celulares funcionavam por meio de tecnologia analógica, os moradores da área rural de Vale do Sol que tinham aparelho em suas residências tinham sinal, sendo 2007 o ano inicial de entrada dos celulares entre os entrevistados. No entanto, no momento da transição para a tecnologia digital, o acesso deixou de ser possível.

A promessa era sempre melhorar o sinal, só que, em vez de melhorar, piorou (Si. P, 47 anos).

Tinha um tempo atrás que nós pegava aqui, no celular, mesmo, da Vivo, né, mas com antena, né. Só que, de repente, sumiu o sinal e não tinha mais nem com antena nem de nenhum jeito (Ad. $P, 45$ anos).

Aqui não pega. Tu gasta um monte em fio, antena, não adianta. (A. A, 47 anos).

Assim, os aparelhos passaram a ter um uso relativo: enquanto se está em casa, são refuncionalizados, sendo utilizados, na maioria das vezes, apenas como relógio, ou, ainda, para ouvir música e tirar fotos, usos mais comuns entre os jovens.

14 Por uma opção das pesquisadoras, as famílias estudadas serão nomeadas pela primeira letra do sobrenome e os sujeitos, por letra(s) do primeiro nome seguida da letra inicial do principal sobrenome. A idade dos entrevistados corresponde ao período da realização da entrevista. 
O emprego do celular propriamente como telefone, para falar e, em alguns casos, acessar à internet, é possível apenas quando eles se deslocam para a sede do município ou para outras cidades, salvo alguns pontos onde o sinal de telefonia é captado, como por exemplo na propriedade dos P., que quando precisam telefonar, sobem um pequeno morro próximo da sua residência ${ }^{15}$.

D. V (30 anos) compreende que o uso que faz do meio é mediado por essa limitação: "Se nós tivesse sinal de telefone aqui como nós estamos sentado agora, com certeza nós ia tá usando bem mais o celular. Mas como tá fixo lá, tá grudado na anteninha, eu não vô ficar parado ali olhando toda hora, ficando mexendo. Vou usar quando precisa." Portanto, a institucionalidade, no que diz respeito às condições de conectividade, atua regulando os usos dessa tecnologia.

Em relação ao telefone fixo convencional, por não haver um cabeamento pronto no interior de Vale do Sol, acaba tendo um custo elevado. Como relatado por R. K (39 anos), a instalação custaria em torno de $\mathrm{R} \$ 3 \mathrm{mil}^{16}$. A única família que tem telefone fixo é a Z. Como se pode verificar comparando o Mapa 1 e o Mapa 2, apresentados anteriormente, a propriedade da família se situa nas cercanias da área urbana do município, ou seja, a proximidade com a sede do município facilita o acesso às TICs. Mesmo assim, lembram que a instalação foi cara, pois foi preciso levar cerca de 800 metros de fios até a residência. Fizeram o investimento, ainda no início dos anos 1990, porque possuíam um comércio, na época.

No regime privado de telefonia, o espaço rural não se mostra vantajoso para as empresas que exploram a oferta desse tipo de serviço. Em algumas residências, a solução oferecida foi uma interface entre telefone fixo e celular. A partir de uma antena instalada na casa, que opera em um raio de 100 metros de distância, o aparelho passa a ter conexão. "É fixo, mas é um celular [risos]”, diz R. K (39 anos).

Outra instituição que possui papel relevante na mediação das relações dos sujeitos com as tecnologias é a escola, que representa na região uma certa ação do Estado. Em relação à apropriação do computador pelas famílias investigadas, 0 principal motivo apresentado pelos informantes - pais e filhos - é colaborar com as demandas escolares dos jovens. Do mesmo modo, a escola é o agente que justifica a instalação do serviço de internet nas casas, sendo associada ao desempenho escolar dos filhos.

Computador mesmo era só pros filhos. Nós nem entendemos. É só pros filho mesmo (A. A, 47 anos).

Por causa de pesquisas de estudo né? [...] Aí ele ia pro colégio, no colégio tinha internet, daí ele precisava internet em casa pra continuar pesquisas de trabalho. E daí já foi entrando pra outros fins, mas a finalidade era por causa do estudo (V.C, 50 anos).

Já tinha feito o curso, é, quando eu ia no colégio (An.P, 23 anos)

Na escola nós acessamos a internet só quando tem aula de computação, ou quando o professor insiste em levar nós pra sala de computação...(Mo.C, 15 anos)

\footnotetext{
15 Essa era a situação das famílias A e P, em 2014 e 2015, momento das duas primeiras visitas nessas famílias. No entanto, em 2017 quando realizamos nova visita, elas tinham adquirido um pacote coletivo de internet juntamente com outras duas famílias vizinhas. Mesmo assim, comentaram que o sinal de celular continuava precário.

${ }^{16}$ Dados de 2014 e 2015.
} 
(...) o primeiro computador que nós compramos foi quando o Ma...C...[irmão, 19] começou a estudar lá na EFA [Escola Família Agrícola], daí a vó compro um pra ele, um grandão, depois ela comprou um note[book], no final, ali quando ele tava no terceiro ano, que tinha que levar junto, mas assim eu acho que o computador nós temos faz um cinco ou seis anos. (Mo.C., 15 anos)

Mesmo no caso da família S, que não tem computador em casa, a justificativa é a escola, uma vez que, como a filha tinha apenas seis anos quando foi realizada a entrevista, o casal de pais ainda não sentia a necessidade de adquirir o equipamento, mas demonstrava ser uma demanda futura à medida que a filha avançasse nos anos escolares: "A N., no colégio, não tem... não acessa a internet, ou computador, ainda, acho que na primeira série, não, né?” (R. S, 34 anos).

\subsection{Socialidade}

Observamos, em diversos momentos, que as condições de gênero e geração incidem, de modo claro, nos usos das TICs. Entre os adultos e idosos, o interesse e, principalmente, o conhecimento acerca do modo de utilizar meios como computador e celular é menor. V.C (50 anos), mesmo tendo acesso à rede em casa, não usa a internet e diz que não sabe "lidar" com o computador: "É uma coisa que parece que tem um branco na frente, às vezes eu quero saber uma coisa e eu peço pra eles [filhos], eles vão ali e me mostram quase a folha pronta. Não tenho a curiosidade de mexer nisso aí". É difícil saber em que medida a dificuldade do manuseio está relacionada com a falta de curiosidade ou se esse "desinteresse" é consequência do desconhecimento sobre o aparato, da falta de capacitação e do medo do desconhecido.

Vários relatos de entrevistados adultos expressam a necessidade de serem ajudados por seus filhos jovens, o que acaba interferindo no tipo de experiência dos mais velhos com os meios de comunicação. Poucos daqueles com mais de 30 anos demonstraram realizar um uso autônomo do computador. A maioria dos pais e mães, durante nossa pesquisa de campo, não usava a internet. Uma exceção foi o casal K. Após um período de uso tutelado pelo filho, R. K (39 anos) aprendeu a usar a internet. "Aí depois, com o passar do tempo, a gente foi gostando daquela tecnologia. [...] Agora se fosse dizer 'agora não quero mais', eu acho que não conseguiria mais". Já a esposa, E. K (37 anos), fez um curso de informática para aprender a usar o computador, e também passou a receber lições do marido, passando a dominar o meio.

Apesar de fazer um uso menos frequente que o casal K, C. V (30 anos) também sabe usar o computador e a internet, o que só foi possível graças à ajuda do filho, de 8 anos, que a encorajou a usar o computador. "Eu sentei, olhei: 'pra que tanto botão, onde que eu vou apertar?’ Medo de apertar... Aí depois ele começou a mexer mais, aí ele começou a me ensinar, né? Aí eu fui indo, devagar, e agora já domino bem."

Percebemos que a sociabilidade provocada pela nova mídia, em destaque neste artigo, é atravessada por outra mediação, da tecnicidade. Os limites e possibilidades que o grupo social encontra com essas TICs passam pelas condições técnicas e cognitivas de seu uso. 
Ainda em termos de interferências geracionais na apropriação e incorporação dos meios, foi recorrente o relato das limitações de assistência de TV impostas por parte dos pais (homens) nos primeiros anos desse meio nas casas dos entrevistados adultos e idosos.

Isso era uma festa, assistir TV. Só que era controlado, tu não podia assistir quando tu queria, né? (Ad. P, 45 anos).

O pai primeiro não deixava nós mexer, só ele ligava pra nós olha os nossos desenho, né?" (C. V, 30 anos).

Daí tinha aqueles programa que vinha assim 'proibido menor de doze anos'. Daí o pai só olhava pra nós, e tinha que ir pra cama, né?. (So. C, 40 anos).

O modo de se relacionar das pessoas, conforme os relatos, também é afetado pela entrada das tecnologias. Mais recentemente, o celular e a internet alteraram os modos de se estar junto e o tempo de diálogo entre pais e filhos, havendo um relativo isolamento entre os membros da família. R. K (39 anos) destaca que "Com a internet, aí, praticamente, entrou dentro de casa, terminou o serviço, cada um pega o seu e fica acessando a internet". De modo semelhante, para V. C (50 anos), as mudanças na rotina dos filhos são claras, já que "qualquer folguinha que tem, eles tão na internet", dificultando um pouco o diálogo: "Em vez de tu sentar, assim, e conversar, ter uma conversa franca, a conversa deles é com a internet. Então ela tirou, vamos dizer, aqueles minutos que a gente podia tá sentado aqui, tomando um chimarrão... A ideia deles tá lá."

R. K também relata um distanciamento entre vizinhos, e vê relação disso com o fortalecimento da presença das novas mídias.

Tá mudando, e acho que vai ficar cada vez mais isolado. Cada família mais para si. Parece que as famílias estão se isolando um pouco. Um não vai mais no vizinho. [...] Hoje, por exemplo assim, nos domingos, quem tem internet, por exemplo: 'ah, vamo lá no vizinho', 'ah, eu vou ficar em casa, vou acessar a internet', né? Posso falar com os meus amigos pela internet. (R. K, 39 anos).

Muito embora esses relatos revelem um certo apartamento, de modo geral, percebemos que as famílias rurais estudadas mantêm práticas de sociabilidade que as aglutinam, até pelo trabalho coletivo da agricultura familiar e pela sobreposição dos espaços de trabalho e de vida, que ocorrem num mesmo espaço geográfico, da propriedade rural. A sociabilidade familiar se dá também na audiência das mídias tradicionais, como rádio escutado pelo coletivo da família no galpão, durante o trabalho com o tabaco, e a audiência conjunta, diariamente, de alguns programas televisivos.

O próprio R. K vê momentos em que as TICs aproximam as pessoas da comunidade, bem como familiares. Dado o isolamento geográfico comum no meio rural, a posse de telefone pode fortalecer relações e fazer com que não se perca contato, incrementando a socialidade. "Bá! Isso [Ruralcel] foi uma novidade, né, uma coisa muito boa! Porque, bá, tu precisava, às vezes, falar com alguém. Então quando nós compramos, aqui, muitos dos vizinhos compraram ao mesmo tempo, aí ficou todo mundo se conectando, né?". 
Observamos usos distintos por gênero. Na maioria das famílias, telefone fixo, celular e computador (redes sociais) são usados frequentemente pelas mulheres para manterem os laços familiares e de amizade. Assim como nas relações presenciais, nas relações mediadas, cabe à mulher estreitar os elos afetivos, seja em contatos rotineiros, seja em situações de doenças ou falecimentos.

Eu tenho uma amiga, ela faz tempo..., ela liga pra mim, eu não sei quanto tempo ela pode..., quando, compra outro bônus, ela pode fala pra mim que não custa nada. Ela sempre bota no meu nome. (Li. Z., 67 anos).

As tecnologias reconfiguram também as relações juvenis e infantis. O grupo de jovens e crianças das famílias descreve sua relação com as mídias como tendo práticas e sentidos distintos, em boa parte, dos adultos. Os usos estão relacionados ao lúdico, na maior parte dos casos, para jogos, realização de fotos, audiência de filmes e desenhos animados. Em algumas situações, as famílias passaram a limitar o tempo nas mídias por associarem seu uso à queda no desempenho escolar, como o caso de Ed.Z (14 anos), que percebe alterações na sua rotina com o acesso à internet: "Quando era antes, eu jogava bola, nem queria nem sabia de internet, hoje, agora, (...) fico quase todo dia. ... mudo assim, eu não, eu não saio mais, às vezes. Eu ia passear com meus amigos, agora eu não vou. É pouco que eu vou".

Para além dos relatos do uso do computador e da internet para realização de trabalhos escolares, em termos de socialidade, os jovens usam o celular e o computador para trabalho e contatos de amizade e namoro. H.Z. (19 anos) toca numa banda nos finais de semana e marca as apresentações pelo Whatsapp, além de usar o telefone móvel e fixo no sindicato rural onde trabalha, assim como usa seu celular para manter contato com sua namorada, que vive numa localidade rural de Vale do Sol distante da sua: “É, no celular é mais questão de, de comunicação, né. Comunicação, fala com outra pessoa, que nem me comunica com minha namorada, que tá mais longe, né." Ou de Ma.C. (19 anos), que usa o celular para os contatos de venda de produtos da empresa agropecuária na qual trabalha, do mesmo modo que D. A. (22 anos) que trocou seu aparelho de celular por um smartphone para intensificar as vendas de vestuário do seu curso, da universidade. E de An. P (23 anos), para quem a posse do artefato representava pertencimento ao grupo: "Pra mim, também foi, assim, interessante, porque quando eu ia no colégio, né, todas as minhas amigas tinham e eu não."

\subsection{Ritualidade}

É comum as famílias se reunirem para uma assistência de televisão em conjunto, de acordo com o horário do dia, constituindo um hábito nas rotinas dos pesquisados. "Bem dizer de noite é quase tudo junto, assim. Tem a da cozinha né, daí senta na cozinha, toma um chimarrão enquanto a vó faz a comida e ficamos olhando TV ali" (Ma. C, 19 anos). Ou seja, após a jornada de trabalho na lavoura, na hora do preparo, durante e logo após as refeições, as famílias costumam reunir-se em torno da TV.

A família $\mathrm{P}$ tem o horário da novela como um momento de reunião. Assim, podem estar junto a vó Am. P (89 anos), já que esse é seu programa preferido. "A vó gosta de todo mundo da gente reunido, né. E ela já é de idade, aí a gente também não quer irrita ela, né? Daí a gente olha junto com ela. Nós também gostamos, eu 
gosto também de olha novela, toma chimarrão, come uma pipoca de noite, né" (P.P, 25 anos). Já a família C, inclusive os mais novos, assiste ao programa do Silvio Santos todos os domingos: "o Silvio Santos que eu não perco" (So.C, 40 anos). Desse modo, o programa faz parte de um "ritual de domingo".

O consumo de TV está de tal modo presente na rotina dos entrevistados, que passa a ser algo irrefletido e, mesmo, considerado um "vício" por alguns. V. C (50 anos) relata que assiste às telenovelas "não por gostar de assistir, é costume, acostuma a olhar, daí parece que tem que olhar todo dia. Não é nem costume, é vício, né? Já fica imaginando os outros dias o que vai dá." A TV é considerada mais "viciante", pois acredita-se que, às vezes, deixam-se compromissos de lado para não se perder determinado programa. Já o consumo de rádio e jornal é avaliado como algo sobre o que se têm mais controle. Além disso, esses dois meios são entendidos como importantes para ter acesso à informação, mais do que a televisão.

A internet também é mencionada como algo que afeta a rotina de forma aguda, podendo fazer com que se perca a noção de tempo. Mo.C (15 anos) diz que a internet acaba sendo uma grande distração, no sentido negativo. "A gente se distrai bastante, tem um serviço pra fazer, eu quero ir ali, mas tem que fazer aquilo lá primeiro, e daí tu deixa de fazer aquilo pra tá ali, e aquilo não tem fundamento, é só bobeiras." D. A (22 anos) pensa de forma semelhante: "A gente fica muito focado na internet e deixa de viver, fazer coisas que a gente fazia antes de ter a internet".

Enquanto os agricultores ouvidos trabalham no galpão ou na roça com o trator - no caso dos veículos mais modernos -, o rádio está sempre ligado, constituindo tanto o ritual que é selecionar o fumo quanto o do plantio e colheita na lavoura. Algumas famílias, como a $\mathrm{P}$, têm rádio no trator, viabilizando ouvir notícias e música enquanto se está na lavoura. A.A (47 anos) contou que, assim como alguns vizinhos, quer ter rádio no trator. Essa escuta do rádio, principalmente no galpão, é coletiva e negociada. Em algumas famílias, como nos $\mathrm{K}$, o tempo de programação juvenil compartilhada durante a secagem do fumo é bastante expressivo, o que vai, de certo modo, contra um estereótipo de relações rígidas e muito hierárquicas entre as distintas gerações no meio rural.

Há também um uso individual das TICs, principalmente pelos jovens, à noite, em seu tempo livre, com destaque para o uso do celular e do computador. Em busca de sinal para a internet, há jovens que se deslocam a um centro da localidade rural, onde há internet wireless da escola disponível, para acessarem a rede, dando nova dinâmica, inclusive, ao local. Do mesmo modo, as mulheres mais velhas e as crianças, as primeiras que participam menos intensamente do trabalho agrícola, permanecem à tarde vendo televisão ou escutando rádio, enquanto realizam atividades domésticas e de cuidado dos filhos.

\subsection{Temporalidade}

No final dos anos 1980, Martín-Barbero chamava a atenção para a presença de novas tecnologias e a constituição de uma "nova etapa de aceleração da modernidade" latino-americana (JACKS; SCHMITZ, 2018, p. 120). Na ocasião, já indicava que abordar essas novas tecnologias na América Latina implicava em conhecer os "destiempos" ou a confluência da "multiplicidade de histórias, com seus próprios ritmos e com suas próprias lógicas” (MARTíN-BARBERO, 1995, p. 43). 
Desse modo, embora não se compreenda a posse de tecnologias de comunicação como sinônimo de modernidade, ou mesmo se adote uma lógica de que quanto mais tecnológico, mais "moderno" e "evoluído", esses artefatos oferecem inúmeras facilidades e, estar alheio a esse universo é, com frequência, lido como um atraso, um viver num tempo passado. Em virtude disso, a apropriação de aparatos como celular, notebook, tablet etc., pode ser compreendido, em certa medida, como uma mudança de temporalidade ou convívio entre temporalidades distintas.

A presença do rádio no trator pode ser relacionada a essa "modernidade". Enquanto as famílias estão na lavoura, plantando e colhendo o tabaco, aquelas que possuem essa tecnologia ocupam o tempo ouvindo músicas e notícias. H.Z (19 anos), que não trabalha na propriedade rural, expressa que o rádio "até conforta, um pouco. Quando tu não tem rádio ligado, tu sente aquele vazio, assim. Preenche aquelas horas." Da mesma forma, quase todos os entrevistados falam da importância da companhia do meio enquanto realizam o trabalho com o fumo no galpão.

O celular é outra tecnologia que modifica a relação com o tempo, seja para que se "ganhe" ou se "perca". As vantagens e desvantagens trazidas pelo artefato são, com frequência, relacionadas a essa relação com o tempo.

Celular é uma ferramenta útil, pra te sobrar mais tempo. Em vez de tu ir vê alguma coisa, que tu tem que ir lá ver, tu pode usar ele pra saber uma coisa de lá longe. [...] Desde pra uma notícia, pra um negócio, pra qualquer coisa ele serve, até pra relógio, até pro horário ele serve também, ele é muito útil, é quase um vício já. (V. C, 50 anos).

No caso de Ri. K (20 anos), a internet preencheu um espaço de tempo importante. "Eu ia dormir às sete horas da noite, eu não tinha o que fazer. [...] Eu nunca gostei muito de TV, então às vezes eu lia alguma coisa e ia dormir mais cedo. Hoje eu vou dormir 10, 11 horas da noite." Mais um exemplo de uso de TIC e sua incidência nos intervalos de tempo dedicados à uma ou outra atividade.

\subsection{Espacialidade}

Para Silverstone, Hirsch e Morley. (1996, p. 49), uma análise visual dos lares permite que se note, nitidamente, "o modelo de diferenciação espacial (privado/ compartilhado; adulto/criança; homem/mulher) que proporciona as bases para a geografia da casa".

Reconhecendo a existência dessa dinâmica, observamos que, em virtude da esfera doméstica ser designada à mulher/agricultora, é possível verificar uma feminização da disposição das tecnologias de comunicação - TV, rádio, computador, telefone fixo/ rural - em combinação com outros objetos, em especial com vasos com flores, toalhas bordadas, ou em crochê, e fotografias da família, tanto na sala de estar quanto na cozinha. Esse tipo de exposição nesses espaços repete-se em todas as casas visitadas.

Por outro lado, outras tecnologias, como os automóveis, usados quase exclusivamente pelos homens - apenas a família Z. foi exceção - no espaço público, bem como a condução dos tratores, faz com que sejam de escolha, posse e manuseio masculinos. Uma agricultora manifestou claramente a discriminação das mulheres no uso do automóvel. 
Além disso, espaços pouco comuns nas casas das cidades, como as varandas, frontais ou de fundos, frequentes nas propriedades visitadas, servem tanto para descanso quanto para receber visitas. A leitura do jornal muitas vezes é realizada nesses espaços, como também na sala, na cozinha e em outras áreas externas.

No que diz respeito aos espaços internos da casa, a importância da cozinha é notória. Distinta das cozinhas urbanas, quase sempre são amplas, bem iluminadas, com janelas com vista para o campo, combinando o lugar de cozinhar, com o de fazer as refeições e o de "estar", frequentemente para se assistir televisão coletivamente. Multifuncionais, também são cotidianamente usadas para ver TV, artefato comumente situado em local que permita assistência coletiva.

Já o computador de mesa recorrentemente figura nas salas de estar das casas visitadas. Isso evidencia um uso compartilhado dessa mídia pela família, sendo, inclusive, alvo de discussões quando um ou outro membro o utiliza em volume alto, atrapalhando a assistência da TV, já que ambos ocupam o mesmo recinto.

Os dormitórios não são mencionados como espaços regulares de acesso aos meios de comunicação. Eles são ocupados com essa finalidade para a assistência de televisão no caso das famílias que possuem mais de dois aparelhos de televisão.

Às TICs, cabe o espaço da casa ou da "rua" (espaços comuns da comunidade e da cidade) e o tempo livre, do lazer e do ócio.

A relação desses sujeitos com o espaço pode ser pensada para além dessa espacialidade habitada, da casa. Ou seja, diz respeito ainda à espacialidade natural, com a presença forte da natureza, e ao espaço do trabalho, que se confunde com os dois anteriores. Assim como as temporalidades da natureza e do trabalho na agricultura se articulam entre si, incidem nos espaços de vida das famílias.

\subsection{Mobilidade}

Com frequência, as facilidades propiciadas pelas tecnologias de comunicação tornam determinados deslocamentos físicos até mesmo desnecessários, substituindo outros serviços. R. K (39 anos), antes mesmo de ter o serviço de internet em casa, já pensava sobre os benefícios que ela poderia trazer. "A gente sempre via na televisão, né, a tecnologia. Então eu sempre ficava pensando 'ah, mas tem muita utilidade". Porém, ao mesmo tempo, considerava seu custo muito alto. Mesmo assim, ao sopesar a "mobilidade" permitida pela tecnologia, passou a avaliar que valia a pena.

\footnotetext{
Na verdade, eu pensava assim 'pô, vamos pagar a internet, pagar quase setenta reais por mês só pra ter internet, qual é a vantagem de ter?’. Então hoje eu vi que, claro, é caro pra pagar, mas eu consigo olhar o meu extrato do banco, eu faço transferência, eu faço pagamentos, então muita coisa eu faço pela internet, coisas que eu teria que me deslocar pro centro. (R. K, 39 anos).
}

Muitos dos informantes destacam a internet como um meio que diminui as distâncias, especialmente no caso dos moradores da área rural, que vivem longe da cidade e de seus serviços. "Nós que somos do interior não fica sabendo das notícias da cidade, lá dos outros estados, daí tu pode pesquisar e ver... pode saber o que tá rolando na cidade e nos outros países." (Mo. C, 15 anos). 
Considerando o contexto geográfico mais isolado em que vivem, o telefone, de qualquer tipo, assume um papel fundamental na vida rural cotidiana.

Pra gente, assim, facilita muito porque a gente que mora afastado, às vezes tem um animal doente, então como é que tu vai entrar em contato com o veterinário? Primeira coisa: liga pro veterinário. Aí então: 'Precisa dar tal e tal medicamento até eu chegar aí. Às vezes até já aconteceu de eu ligar pra agropecuária, encomendar o remédio pra vim pelo ônibus, então eu nem precisei me deslocar pra buscar o remédio. Tudo por telefone, né? (R. K, 39 anos).

E os jovens veem no celular e no computador uma via de integração a um mundo distante fisicamente da ruralidade vivenciada e, principalmente, uma opção de lazer num contexto onde atividades dessa ordem são escassas. Pontuamos, por último, a utilidade para "aproximar" parentes distantes, "matar a saudade", papel desempenhado, para a família toda, pela mulher.

\section{Os sujeitos e suas práticas com as tecnologias da comunicação}

A utilização do Mapa de chaves teórico-analíticas para um estudo socioantropológico de TICs nos permitiu tratar das condições de facilitação e impedimento na apropriação de TICs; da convivência de múltiplos espaços (urbano/rural/escola/casa/lavoura, entre outros) e tempos (do trabalho, livre, entretenimento, estudo); dos movimentos pendulares de deslocamento, seja físico ou virtual; dos rituais de incorporação das distintas tecnologias de comunicação; das relações sociais configuradas por esses mesmos artefatos situadas em uma determinada ruralidade. $\mathrm{E}$, do modo mais abrangente, de referendar uma perspectiva de relações de coprodução entre tecnologia e sociedade.

Figura 2 - Mapa de chaves teórico-analíticas para um estudo socioantropológico de TICs - Desdobramento das mediações em uma ruralidade do Sul

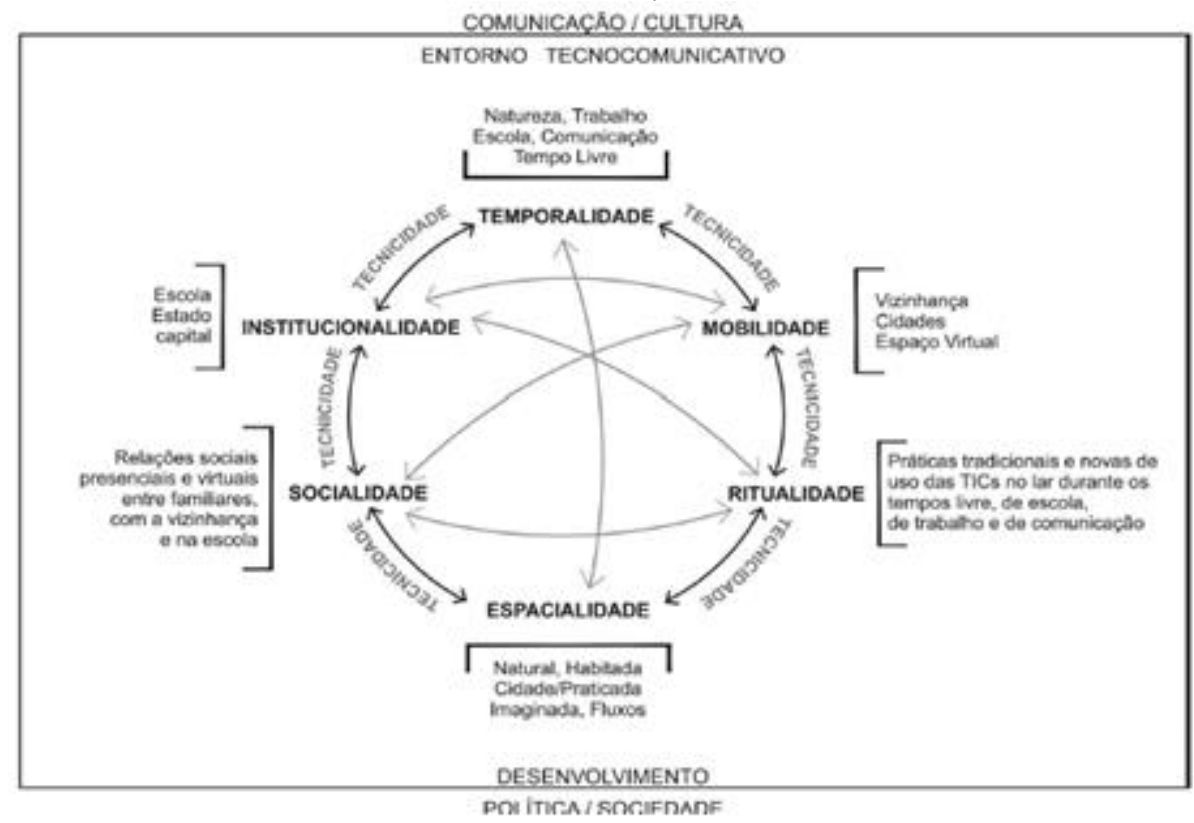

Fonte: (FELIPPI, 2019, p. 187). 
Além das observações pontuais e empíricas já expostas, referendamos que, como nos ensina Martín-Barbero, a investigação tratou de uma realidade englobada por um "entorno tecnocomunicativo". Mais especificamente, uma Microrregião onde se destaca o município de Vale do Sol, localidade onde foi realizada a pesquisa de campo, atravessada por dois movimentos contraditórios e concomitantes: de inclusão e de exclusão digital. Isto é, uma realidade caracterizada pela presença de processos particulares de apropriação e incorporação de tecnologias de informação e comunicação (TICS) por parte de um determinado grupo social, famílias agricultoras, inseridas na cadeia agroindustrial do tabaco.

Considerando a desatenção sobre o espaço rural na área da Comunicação, em especial quando se trata de uma pesquisa sobre a presença e os múltiplos usos de tecnologias de informação e comunicação que adota um entendimento de relações mútuas entre tecnologia, cultura e sociedade, bem como a carência, no âmbito dos estudos sobre desenvolvimento regional, de uma perspectiva desse tipo na análise de referido objeto, ambicionamos ter construído uma tessitura interdisciplinar dessas duas áreas, possibilitando o tratamento de uma realidade conforme indicações anteriores.

A partir de uma determinada problematização teórica que privilegiou sua afinidade com os estudos culturais ou, pelo menos, com uma versão deles, deu-se preferência à materialidade social da cultura e à sua dimensão simbólico-política. $E$, também, a um compromisso com uma determinada forma de estudar as TICs, entendendo que a relevância da tecnologia extravasa seu próprio espaço e papel de aparato tecnológico, seu caráter meramente instrumental, transbordando suas repercussões para a vida social como um todo, constituindo novas formas de sociabilidade e assumindo uma função ritual tanto em momentos excepcionais quanto na normalidade da vida cotidiana.

Contudo, é importante ainda ressaltar o esforço que empreendemos em focar na tensão entre o protagonismo dos sujeitos e suas práticas criativas com as TICs e a pressão das determinações estruturais como dimensão substantiva na limitação de tal capacidade (REGUILLO, 2004). Essas últimas, na trama teórico-analítica, estão configuradas pelo "entorno tecnocomunicativo" que é o ecossistema comunicativo que estrutura e constitui a vida social, e pelas mediações da temporalidade, espacialidade e institucionalidade. Portanto, tais mediações compõem forças objetivas que controlam a ação dos sujeitos. Já a capacidade criativa e as experiências dos sujeitos estão expostas, sobretudo, nas mediações da mobilidade, ritualidade e socialidade que impactam tanto sua atividade produtiva quanto social, familiar e afetiva. Consideramos ainda que é possível observar vitalidade e dinamismo dos sujeitos na espacialidade, especificamente, nos espaços imaginados, e na temporalidade no que diz respeito ao tempo livre, embora aí também se manifeste a pressão estrutural, como já foi dito.

A mediação da tecnicidade é constituinte e atravessa ambos processos - das determinações estruturais e da capacidade criativa dos sujeitos. E, de modo geral, a estratégia teórica tornou-se uma potente alternativa para dar conta da fluidez com a qual a mídia se espraia na sociedade, como também nas nossas vidas. Ancora-se aí a conveniência de situar a investigação no âmbito das questões em torno da mídia na vida cotidiana. E, notadamente, com uma via conectada ao exame das diversas 
formas de sociabilidade construídas em contextos particulares e, principalmente, mediadas pela tecnicidade. São essas as conclusões gerais que se alcançou, de (re)configurações tanto de um espaço rural quanto de um modo de vida particular, ali concebido pelos sujeitos, por meio da ação das TICs.

\section{REFERÊNCIAS}

CETIC.BR - Centro de estudos sobre as tecnologias da informação e da comunicação. TIC Domicílios, 2018. Disponível em: http://data.cetic.br/cetic/explore?idPesquisa=TIC_DOM. Acessado em: 24 set. 2019.

DIZARD, Wilson. A nova mídia - A comunicação de massa na era da informação. Rio de Janeiro: Jorge Zahar, 2000.

ESCOSTEGUY, Ana Carolina. As tecnologias de informação e comunicação em perspectiva teórico-analítica. In: ESCOSTEGUY, Ana Carolina et al. As tecnologias da comunicação no cotidiano de famílias rurais: (Re)configurações de uma ruralidade. Santa Cruz do Sul: EDUNISC, 2019, p. 15-31. Disponível em: https://www.unisc.br/pt/home/editora/ebooks?id_livro=485 Acesso em: 12 set. 2019.

ESCOSTEGUY, Ana Carolina D.; SIFUENTES, Lírian; BIANCHINI, Aline. O uso de tecnologias por famílias agricultoras: uma reflexão metodológica. Revista Comunicação, Mídia e Consumo, São Paulo, v. 13, n. 38, p. 97-115, set.-dez. 2016. Disponível em: http://revistacmc.espm.br/index.php/revistacmc Acesso em: 16 dez. 2019.

FELIPPI, Ângela Cristina Trevisan; OLIVEIRA, Vinícios Gonchoroski de; DORNELLES, Mizael. O território em estudo: microrregião de Santa Cruz do Sul e Vale do Sol. In: ESCOSTEGUY, Ana Carolina et al. As tecnologias da comunicação no cotidiano de famílias rurais:

(Re)configurações de uma ruralidade. Santa Cruz do Sul: EDUNISC, 2019, p. 53-74. Disponível em: https://www.unisc.br/pt/home/editora/e-books?id_livro=485 Acesso em: 12 set. 2019.

FELIPPI, Ângela Cristina Trevisan. (Re) Configurações de uma ruralidade por meio das TICs. In: ESCOSTEGUY, Ana Carolina et al. As tecnologias da comunicação no cotidiano de famílias rurais: (Re)configurações de uma ruralidade. Santa Cruz do Sul: EDUNISC, 2019, p. 182-191. Disponível em: https://www.unisc.br/pt/home/editora/e-books?id_livro=485 Acesso em: 16 dez. 2019.

FELIPPI, Ângela C. T.; ESCOSTEGUY, Ana Carolina D. Juventude rural e novas formas de sociabilidade: um estudo do uso do celular no Sul do Brasil. Revista Latino-americana de Ciências da Comunicação, São Paulo, v. 14, n. 16, p. 140-150, 2017. Disponível em: https://www.alaic. org/revista/index.php/alaic/article/view/906. Acesso em: 2 out. 2018.

IBGE. Censo demográfico de 2010. 2010. Disponível em: https://sidra.ibge.gov.br/pesquisa/censo-demografico/demografico-2010/inicial. Acessado em: 17 jan. 2018.

IBGE-Cidades. Brasil em síntese. 2018. Disponível em:

https://cidades.ibge.gov.br/brasil/rs/vale-do-sol/panorama. Acessado em: 24 set. 2019. 
JACKS, Nilda; SCHMITZ, Daniela. Os meios em Martín-Barbero: antes e depois das mediações. Matrizes, São Paulo, v. 12, n. 1, p. 115-130, jan./abr. 2018. Disponível em: https://www.revistas.usp.br/matrizes/. Acessado em: 16 dez. 2019.

MARTíN-BARBERO, Jesús. América Latina e os anos recentes: o estudo da recepção em comunicação social. In: SOUZA, Mauro Wilton (org.). Sujeito, o lado oculto do receptor. São Paulo: Brasiliense, 1995. p. 39-68.

MARTÍN-BARBERO, Jesús. Dos meios às mediações. Rio de Janeiro: UFRJ, 2003.

MARTÍN-BARBERO, Jesús. Uma aventura epistemológica - Entrevista. Matrizes, São Paulo, (2) 2, p. 143-162, 2009a. Disponível em: https://www.revistas.usp.br/matrizes/. Acessado em: 16 dez. 2019.

MARTíN-BARBERO, Jesús. Jesús Martín-Barbero: as formas mestiças da mídia. Entrevista com Jesús Martín-Barbero a Marluci Moura. Revista Pesquisa Fapesp, São Paulo, n. 163, p. 10-15, 2009b. Disponível em: https://revistapesquisa.fapesp.br/. Acessado em: 16 dez. 2019.

MARTíN-BARBERO, Jesús. Dos meios às mediações: três introduções. Matrizes, 2018, n. 1, v.12, p. 9-31. Disponível em:

<http://www.revistas.usp.br/matrizes/article/view/145681/139737>. Acessado em: 26 dez. 2018.

QUIROZ, Juliana; VÉLEZ, Santiago. Tecnología y sociedade: una aproximación a los estudios sociales de la tecnología. Revista CTS, Buenos Aires, v. 9, n. 26, p. 129-144, maio 2014. Disponível em: http://www.ppgcts.ufscar.br/arquivos/disciplinas/cts-014-topicos-especiais12-desafios-em-pesquisa-em-cts. Acessado em: 16 dez. 2019.

REGUILLO, Rossana. Los estudios culturales. El mapa incómodo de un relato inconcluso. Barcelona, 2004.

SIFUENTES, Lírian; BIANCHINI, Aline ; RIBAS, João Vicente . A metodologia na pesquisa de campo. In: In: ESCOSTEGUY, Ana Carolina et al. As tecnologias da comunicação no cotidiano de famílias rurais: (Re)configurações de uma ruralidade. Santa Cruz do Sul: EDUNISC, 2019, p. 75-101. Disponível em: https://www.unisc.br/pt/home/editora/e-books?id_livro=485 Acessado em 12 set. 2019.

SILVEIRA, R. L. L. et al. Rede agroindustrial do fumo e a dinâmica de organização espacial e de usos do território na região Sul do Brasil. [relatório de pesquisa]. Santa Cruz do Sul, RS. Universidade de Santa Cruz do Sul, 2011.

SILVERSTONE, Roger; HIRSCH, Eric; MORLEY, David (ed.). Los efectos de la nueva comunicación - El consumo de la moderna tecnologia en el hogar y en la família. Barcelona: Bosch, 1996. p. 39-57.

WAJCMAN, Judy. Esclavos del tempo. Vidas aceleradas en la era del capitalismo digital. Paidós: Barcelona, 2017. 
Ana Carolina Escosteguy. Universidade Federal de Santa Maria - UFSM.

Professora Pesquisadora do CNPq. E-mail: carolad2017@gmail.com .

Ângela Cristina Trevisan Felippi. Universidade de Santa Cruz do Sul - UNISC.

Professora Pesquisadora. E-mail: angelafe@unisc.br

Lírian Sifuentes. Televisão Educativa de Porto Alegre - TVE. Jornalista. E-mail: lisifuentes@yahoo.com.br

Como citar: ESCOSTEGUY, Ana Carolina D.; FELIPPI, Ângela Cristina Trevisan; SIFUENTES, Lírian. Reconfigurações do espaço rural e do cotidiano familiar: os sujeitos e suas práticas com as tecnologias de comunicação. Redes (St. Cruz Sul, Online), Santa Cruz do Sul, v. 25, n. 1, jan. 2020. ISSN 1982-6745. DOI: https://doi.org/10.17058/redes.v25i1.14243.

\section{CONTRIBUIÇÃO DE CADA AUTORA}

Fundamentação teórico-conceitual e problematização: Elaboradas principalmente pelas autoras Ana Carolina D. Escosteguy e Ângela C. T. Felippi, sendo a primeira responsável principalmente pelas discussões relativas à Comunicação, e a segunda pelas contribuições oriundas do Desenvolvimento Regional. A fundamentação e problematização pertinentes à Metodologia foram realizadas principalmente pela autora Lírian Sifuentes.

Pesquisa de dados e análise estatística: A pesquisa de dados foi realizada pelas autoras e demais membros do grupo de pesquisa, em diversas incursões a campo. A análise dos dados, como apresentada no artigo, através da sistematização por mediações, foi desenvolvida principalmente pela autora Lírian Sifuentes. (A análise é qualitativa e não se realiza análise estatística)

Elaboração de figuras e tabelas: Figuras foram elaboradas por membros do grupo de pesquisa.

Fotos

Não são utilizadas fotos.

Elaboração e redação do texto: A elaboração inicial do artigo é das três autoras. A redação do texto na forma como se apresenta neste artigo foi inicialmente feita por Lírian, com revisão de conteúdo por Ana Carolina D. Escosteguy, e de conteúdo e formatação de acordo com as normas da revista Redes, por Angela C. T. Felippi.

Seleção das referências bibliográficas: A seleção foi feita pelas três autoras, com destaque para o trabalho de Ana Carolina D. Escosteguy, responsável principal pelo projeto do qual esse artigo resulta. 